\title{
Country of Origin Labeling: A Legal and Economic Analysis
}

\author{
John VanSickle•, Roger McEowen••, C. Robert Taylor..., \\ Neil E. Harl...., and John Connor.....
}

\section{Introduction}

The Country of Origin Labeling (COOL) provisions in the 2002 Farm Bill (hereinafter "Labeling Legislation") requires retail sellers of several food commodities to inform consumers of the country of origin of certain commodities. ${ }^{1}$ There has been considerable debate and several competing claims regarding the costs of this program despite the fact that USDA has not yet designed the regulations to implement mandatory labeling. However, attempts to quantitatively or qualitatively analyze the benefits of labeling have been absent until recently in the public debate though the methodology for doing so is available.

In this paper, we provide both a legal and economic analysis of the Labeling Legislation. Our significant findings are as follows:

- The least cost alternative regulatory scheme that complies with existing law is to presume that all covered commodities are of U.S. origin while tracking existing marks of origin on imported products. Other options are either too expensive or likely to violate the Labeling Legislation itself.

- Tracking imported product labels as to country of origin while presuming other product to be that of U.S. origin complies with WTO rules and other trade laws.

- Producers of covered commodities are not subject to USDA jurisdiction under the Labeling Legislation unless they are vertically integrated so as to perform the functions of preparer, storer, handler, distributor or retailer of a covered commodity.

- The benefits of labeling include consumer information, consumer choice, preservation of confidence in the food system, increased ability for consumers to identify food items subject to a recall, lessened costs incurred in contamination incidents, and consumer willingness-to-pay for labeling.

- The benefits of labeling substantially outweigh the cost.

- Consumer willingness-to-pay for labeling as to country of origin appears to be very significant. Existing studies suggest that the aggregate willingness-to-pay for labeling of beef alone is in excess of $\$ 3.5$ billion.

- Past estimates of cost by USDA and others are substantially overblown due to errors in both legal and economic assumptions.

- There is no reason to believe that consumer demand for covered commodities will be negatively affected by increased costs attributable to record keeping for labeling.

- The cost of record keeping relating to the labeling legislation is between $\$ 69.86$ million and \$193.43 million, which is 90 to $95 \%$ less than the USDA cost estimate. This cost translates into less than one-tenth of a cent per pound for the covered commodities as consumed by U.S. citizens. 


\section{Legislative Provisions}

The Labeling Legislation applies to beef, pork, and lamb in the form of whole muscle cuts and ground meat. It also applies to fish (farm-raised or wild), peanuts, fruits and vegetables. ${ }^{2}$ These commodities are termed "covered commodities" in the law, and for purposes of this paper. Covered commodities must be exclusively produced and processed within the United States to be deemed of U.S. origin. ${ }^{3}$

\section{A. What industry conduct is affected?}

Private actor conduct is regulated by two types of mandatory "information provisions" and through a discretionary "verification provision." The primary "information provision" mandates that retailers provide information to consumers as to the country of origin of the covered commodities. ${ }^{4}$ The method by which consumers are to be notified is through a "label, stamp, mark, placard," or other type of signage that is "clear and visible" at the point of sale. ${ }^{5}$

The other information provision of the Labeling Legislation requires that "any person in the business of supplying a covered commodity to a retailer shall provide information to the retailer indicating the country of origin of the covered commodity." 6 We interpret this provision to impose a duty upon direct suppliers, rather than upon all upstream suppliers, because only direct suppliers to retailers can, in practice, provide the information to a specific retailer. Indirect suppliers to retailers cannot provide that information to the retailer because of lack of knowledge of who the particular retail seller will be.

The "verification provision" is discretionary, rather than mandatory, in the Labeling Legislation in that the Secretary of Agriculture "may" require that any entity "that prepares, stores, handles, or distributes a covered commodity for retail sale maintains a verifiable record keeping audit trail that will permit the Secretary to verify compliance with" the law. ${ }^{7}$ We will treat this provision as mandatory because it appears from public comments and from the previously issued Voluntary Labeling Guidelines that the Secretary fully intends to require such an audit trail. The purpose of the verification provision is to maintain reasonable integrity and credibility in the labeling scheme.

However, mandatory identification systems are prohibited. ${ }^{8}$ This prohibition was included in the bill to avoid the concerns of livestock producers who feared potential liability arising from the ability of regulators and others to trace back meat products to the farm of origin. Thus, while the Secretary must propound regulations to allow consumers to identify the country of origin, the regulations cannot go further to identify the farm of origin. ${ }^{9}$

\section{B. Who is covered by the law?}

Virtually every business in the stream of commerce of covered commodities is subject to regulation under the Labeling Legislation after the ownership of the product is transferred from the producer to the first buyer. 
Retailers are covered by the act because they are charged with providing the ultimate piece of information, that of country of origin, to the consumer. ${ }^{10}$ This is the primary information provision of the law. Retailers are exempt if they sell less than $\$ 230,000$ per year of either fruits and vegetables or of all covered commodities. ${ }^{11}$ Food service establishments, such as restaurants and cafeterias, are exempted from the requirement to provide information to consumers. ${ }^{12}$

Businesses that prepare, store, handle, or distribute covered commodities are also covered in that the Secretary may, and likely will, require that they maintain a "verifiable record keeping audit trail" to verify compliance. ${ }^{13}$

Farmers, ranchers, growers and fisherman are likely not within the purview of the Labeling Legislation because they are not specifically identified as a regulated entity. When Congress intends to regulate or affect producers, it so specifies. For example, 7 U.S.C. $\S 2302$ (b) defines "producers" as "a person engaged in the production of agricultural products as a farmer, planter, rancher, dairyman, fruit, vegetable, or nut grower."

Additionally, producers of livestock do not produce covered commodities, i.e. whole muscle cuts of meat or ground meat. ${ }^{14}$ Rather, they produce live cattle, swine and sheep. For example, "swine" is defined as a live animal while "pork" is defined as meat from a porcine animal in 7 U.S.C. $\S 198$. Fisherman or fish farmers may not be within the purview of the Labeling Legislation because they do not produce covered commodities or because they are not regulated entities.

However, vertically integrated producers are regulated entities if they also perform the functions of preparing, storing, handling or distributing the products. Examples include vertically integrated pork production and processing companies such as Smithfield Foods in pork and many vegetable producers that also pack and ship their own, and perhaps others', produce.

The labeling program will not be mandatory until September 30, 2004. ${ }^{15}$ Retailers and other covered entities will have to comply at that time. Until then, labeling will be voluntary. The United States Department of Agriculture (USDA) was required to propound guidelines (not regulations) for voluntary labeling by September 30, 2002, ${ }^{16}$ and did so on October 11, 2002. ${ }^{17}$ By September 30, 2004, the USDA is to have in place regulations to implement this law. ${ }^{18}$

\section{When can violations be prosecuted?}

The enforcement regime is quite relaxed. The law is enforceable against retailers only if they "willfully" violate the law. ${ }^{19}$ A fine cannot be levied unless the Secretary has first provided the retailer with notice of a violation as well as a 30-day opportunity to correct the problem. ${ }^{20}$ This requirement of "willfulness" is significant in that retail supermarkets have to engage in conduct that is affirmatively fraudulent before they may be fined, and then only up to $\$ 10,000$. The retailer will not be liable for negligent violations, or 
innocent mistakes. In other words, if a retailer innocently relies upon potential misrepresentations of suppliers, the retailer cannot face enforcement liability.

Covered entities that are not retailers are subject to a slightly different enforcement standard. The Labeling Legislation incorporated the enforcement provisions contained in the Livestock Mandatory Reporting Act of 1999 for packers, processors, handlers, etc. ${ }^{21}$ That standard requires that the Secretary must consider several factors before issuing a fine including "the gravity of the offense, the size of the business involved, and the effect of the penalty on the ability" to continue in business. ${ }^{22}$ Though the standard for issuing a fine differs here from the retailer standard, we believe it prudent and probable that the Secretary will require a finding akin to willfulness prior to doing so. We can see no reason to treat covered entities in different ways under the enforcement regime. The result would be that businesses that make innocent mistakes, or rely on the misrepresentations of others, will not be fined.

\section{COOL Implementation: The Proper Regulatory Scheme}

We are now in the implementation stage of the Labeling Legislation. While USDA issued Voluntary Guidelines on October 11, 2002, the regulations have not yet been written. The optimum regulatory scheme is one that: (1) complies with the Labeling Legislation and trade laws; (2) lessens the burdens on private entities to the extent possible; (3) lessens the burden on USDA to the extent possible; and (4) reduces the risk of misrepresentation.

The debate during the implementation period has focused upon three basic regulatory alternatives: (1) a Third Party Verification Rule where all representations as to the origin of all covered commodities is verified by third parties; (2) a Self Verification Rule where all representations as to the origin of all covered commodities are merely represented by the market participants in the chain of commerce; and (3) a Presumption of U.S. Origin Rule where the regulations presume that all products are of U.S. origin unless a foreign mark of origin is on the product.

In our view, the Presumption of U.S. Origin Rule is most likely to comply with the law, lessens the burden on industry and government, and sufficiently deters potential label misrepresentation.

\section{A. Third Party Verification Rule: The Most Undesirable Option}

The early stages of the COOL implementation debate included serious discussions of the potential for requiring third party verification of all covered commodities at the producer level. The third party verification discussion arose primarily from a sentence in the Voluntary Guidelines which stated that self certification would not be sufficient. ${ }^{23}$ The Labeling Legislation itself does not require third party verification. The debate seems to have moved away from this possibility as per public representations by USDA officials, but we will briefly discuss it here. 
A Third Party Verification Rule would be the most expensive system for the food sector to implement. It would foster a whole new industry of third party verifiers. Indeed, we are aware of some companies that have been promoting themselves to provide such services as a significant potential revenue generator.

While third party verification may be the most likely to reduce the risk of misrepresentation, such a system's costs far outweigh the risks. This becomes clear if we compare other regulatory schemes where the reporting of information is the core issue. The Livestock Mandatory Price Reporting Act of 1999, for example, requires meat packers to report prices without third parties verifying the truthfulness of the reporting. Further, the income tax reporting system does not require third party verification, but rather a self verifying "honor system" subject to potential audit. Neither of these information reporting systems requires third party verification. Note that periodic compliance audits are not third party verification, but are tools to ensure that self verification actions remain reasonably accurate.

\section{B. Self Verification Rule: A Likely Unlawful Option}

The most popular basic regulatory option in the current debate is one that would require producers and others to self verify the country of origin of all covered commodities. This system would presumably require all sellers, including producers, to provide country of origin information to all buyers in privity with them. Ultimately the retail food store receives that information and conveys it to the consumer in some form. The system would be policed by the practice of periodic audits by the USDA and the subsequent possibility of civil penalties.

The Self Verification Rule is more in line with other regulatory regimes governing the reporting of information for a public purpose in that third parties are not necessary to verify truthfulness in every transaction. Thus, it is far less costly than a third party system.

In addition, there is no need to create a whole new record keeping system. Regulated entities keep a number of records in the regular course of business. Those records are likely sufficient to allow them to identify the origin of the product. For producers of covered commodities, production records are more than sufficient. For other covered entities that are not producers, they will simply need to add a line on their purchase documents to indicate the country of origin of the product. Information as to the origin of a product can be placed on a bill of lading, an invoice, an affidavit, or any standardized transaction-relevant form. Indeed, USDA has published an online document stating the types of records that auditors will look for to determine compliance. ${ }^{24}$ The records listed are what any properly run business keeps in the ordinary course of operations.

Serious concern has been expressed about the Self Verification Rule as currently discussed by USDA because meat packers and retail food stores have publicly expressed their intention to require their suppliers to consent to open their books for random private audits by the buyers. 
USDA officials have stated that they cannot control private conduct. However, USDA can easily remove any justification for such intrusive business practices by merely allowing buyers to rely in good faith upon the representations of sellers as to the country of origin of the product. A specific provision in the future regulations allowing such good faith reliance, combined with the statutory enforcement language that only willful violations are subject to fine, amounts to a safe harbor for regulated entities who do not knowingly or fraudulently mislabel products. There would then be no business justification for allowing such private random audits.

However, the Self Verification Rule as contemplated by USDA may not be lawful under the Labeling Legislation. Producers are not specifically named as entities that the Secretary may regulate under the law. In other areas of the federal agricultural statutes, Congress specifically identified producer if it intended them to be subject to a regulatory scheme. Further, producers of livestock do not produce a covered commodity, but rather live animals. This point was developed above in the prior section.

Thus, the USDA should try to avoid a Self Verification Rule that imposes any regulatory burden on U.S. producers because the Secretary likely does not have jurisdiction over them.

\section{The Presumption of U.S. Origin Rule: The Preferred Option}

\section{The Nature of the Rule}

The Presumption of U.S. Origin Rule is a shorthand title for a regulatory reporting scheme in which all products are presumed to be of U.S. origin unless they carry a mark from another country. The corollary to this presumption is a duty to maintain the mark of origin that is currently required on most imported products as a condition of entry into this country. This scheme avoids the problem of lack of jurisdiction over U.S. producers, complies with international trade norms, and minimizes the regulatory burden caused by the program.

First, the regulatory burden is significantly reduced by the Presumption of U.S. Origin Rule by eliminating a large number of affected entities. U.S. producers are a whole category of entities left untouched, except for the few that import young animals to grow for later sale. Many small processors, packers and other handlers would be de facto exempt because they do not engage in the trade of imported product (though statistics are not available to quantify this number).

Second, the problem of lack of jurisdiction over U.S. producers is eliminated because this regime does not rely upon the producer as the trigger point to input the first information as to country of origin that follows the product to the consumer. Rather, the trigger point relied upon is the passage of covered commodity over the border, through customs. The USDA acknowledged in the Voluntary Guidelines that several current federal laws require most imports, including food items, to bear labels or other information designating the country of origin. ${ }^{25}$ 
Third, the Presumption of U.S. Origin Rule complies with international trade rules. The relevant rule arises from the membership of the United States in the World Trade Organization (WTO). Though some have argued that a Presumption of U.S. Origin Rule would violate the general proposition that a WTO member must afford the same treatment to foreign goods that it does to domestic product, Article IX of the General Agreement on Tariffs and Trade (GATT) allows member nations to require marks of origin on goods imported from any other WTO Member.

\section{Compliance with International Trade Norms}

Article IX:3 of GATT provides that "[w]henever it is administratively practicable to do so, contracting parties should permit required marks of origin to be affixed at the time of importation." This is currently the practice in the U.S. Further, the laws and regulations relating to "the marking of imported products shall be such as to permit compliance without seriously damaging the products, or materially reducing their value, or unreasonably increasing their cost." GATT Article IX:4. Thus, the U.S. can require any "reasonable" means to mark the imported products as to their origin. However, the U.S. cannot go beyond requiring a mark of country of origin to further specify the producer or place of origin. ${ }^{26}$

The U.S. currently requires imported products of nearly all types, far beyond the scope of covered commodities under the Labeling Legislation, to bear a mark of origin upon entry to the United States. These statutory marking requirements are provided for in 19 U.S.C. $\S 1304$ (a) which provides the general rule that all imports must bear a mark of origin. These rules are administered through the U.S. Customs Service under the ultimate authority of the Secretary of the Treasury. The Treasury Secretary has the discretionary authority to exempt certain merchandise from the marking requirement. ${ }^{27}$ This list of exempted products is called the "Jlist", so named for section 1304(a)(3)(J) of the statute U.S. trade laws provide that if the "ultimate purchaser" knows the country of origin of the imported article, then the article need not be marked. ${ }^{28}$ The "ultimate purchaser," under 19 U.S.C. $\S 1304$, is defined in 19 CFR $\S 134.1(d)$ as generally the last person in the U.S. who will receive the article in the form in which it was imported.

Cattle, swine and sheep imported for immediate slaughter need not bear such a mark for COOL purposes because the packer that is importing the animals knows the country of origin because the packer is the party engaging in the import transaction. ${ }^{29}$ Thus, the "ultimate purchaser" of livestock is the packer/slaughterer. Since the packer knows the country of origin of imported livestock, it can then convey that information downstream to subsequent purchasers of meat.

The ultimate purchaser, for import purchases, of covered commodities such as meat, fruits, vegetables, nuts, etc. also knows the origin of those commodities. Those ultimate purchasers are regulated entities under the Labeling Legislation that have a duty to pass that information to downstream purchasers. 
While live animals are on the "J-list" and do not bear a mark of origin for customs purposes,${ }^{30}$ they can be identified in other ways. Live animals imported for slaughter must be accompanied by papers that include information such as the country of origin. ${ }^{31}$ That information can be identified by the packer who imports the animals and who can then transmit the information to downstream buyers, including retailers. Live animals imported for further feeding and other purposes, such as dairy cattle, breeding cattle, feeder cattle and feeder pigs, require further discussion.

As a general proposition, the USDA can work with the U.S. Treasury to remove livestock from the J-list in order to facilitate proper identification for labeling purposes. A tag, brand or tattoo could be used to convey the origin information to the packer. However, many animals are currently marked for health purposes under USDA rules. Those marks can be used to identify the origin of the animals by the packer that purchases them.

Additionally, USDA currently has the authority to regulate the importation of animals, including requirements that the animals bear documentation or markings denoting their origin. ${ }^{32}$ The USDA requirements take precedence over the Customs Service's J-list in that USDA can require such markings even despite the fact that live animals are on the J-list. ${ }^{33}$ USDA's Animal and Plant Health Inspection Service (APHIS) carries out these functions. Pursuant to this authority, USDA could choose to modify the appropriate health rules so that the animals imported can be identifiable for labeling purposes. As stated above, the prohibition of mandatory identification systems in the Labeling Legislation serves to prevent trace-back to the farm of origin and does not affect attempts to designate the country of origin.

As a practical matter, there are very few animals that must be identified by means other than those means which exist now. As to cattle, we need only identify approximately 593,000 head of cattle originating in Canada and not destined for immediate slaughter. Trade data from the USDA's Foreign Agriculture Service (FAS) website shows the following. ${ }^{34}$ A total of 2.5 million live cattle were imported into the United States in 2002, overwhelmingly from Canada and Mexico (four head were imported from Australia). Of those cattle, 1.02 million were imported from Canada and 407 were imported from Mexico for direct slaughter by packers who knew the origins of the cattle under existing law as stated above.

The remaining 1.41 million head of imported cattle were for feeding or other purposes, not for direct slaughter. Of those feeder and other cattle, 816,000 were Mexican cattle. All Mexican cattle coming into the U.S. for further feeding must be marked with a permanent "M" brand for steers and an "Mx" brand for heifers. ${ }^{35}$ These marks are highly visible at 2-3 inches high. Packers can readily identify these cattle when they are sorted at the packing plant for slaughter. Therefore, only 593,130 head of cattle entered the United States in 2002 without either existing marks of origin or without the need for marks of origin because the cattle's origins were known to the persons importing the cattle for direct slaughter. 
The FAS agricultural trade data ${ }^{36}$ similarly show that the number of swine and sheep that must be tracked under this system are minimal. For example, virtually all swine imported for immediate slaughter came from Canada in the amount of 1.81 million head. Because packers engaged in the import transaction know the origin of the swine, no mark of origin is needed.

Additionally, approximately 3.93 million head of feeder pigs and 139,000 head of sheep were imported into the United States. ${ }^{37}$ The National Center for Import and Export, a subdivision of USDA-APHIS Veterinary Services, says that all swine imported from Canada must have a health certificate ${ }^{38}$ which contains information that can identify the specific animals. That identification system, according to the National Center for Import and Export, includes any permanent mark such as an ear tag or tattoo with a unique number. Thus, feeder swine are already identified with a permanent mark that packers can use to identify their origin upon later slaughter. Imported sheep, however, may need to have an additional mark for a packer to identify them after being further grown for slaughter.

Thus, the number of animals that are not currently subject to identification for labeling purposes is very small. Only 0.6 percent of all cattle and calves need be identified for COOL purposes. On January 1, 2003, all cattle and calves in the United States totaled 96.1 million head. ${ }^{39}$ USDA needs only to identify the 593,130 head of feeder cattle coming from Canada.

Only 1.7 percent of sheep and lambs are not of known origin and need be identified. As of July 1, 2002, the latest data available, all sheep and lambs in the United States totaled 8.1 million head. ${ }^{40}$ USDA needs only to effect a foreign mark on 139,000 head of imported sheep in order to effectively implement the Labeling Legislation.

Lastly, it appears that no additional means need be implemented to identify swine under the Presumption of U.S. Origin Rule because all feeder swine already bear a permanent mark for health purposes upon entry to the U.S.

\section{Conclusion: Rationale of the Rule}

In sum, under the Presumption of U.S. Origin Rule, the USDA need not track the origin of every unit of fruits, vegetables, peanuts, fish, beef, pork and lamb. This regulatory scheme recognizes the reality that the vast majority of covered commodities are produced exclusively in the United States. The USDA can merely focus on requiring that the information contained on existing marks of origin is preserved for the benefit of consumers. Those marks now exist in compliance with international and U.S. trade laws. All that is necessary is the recommended minor modifications of current regulations to identify, with marks of origin, the few imported livestock for which the origin is not presently determinable by marks or otherwise. These livestock constitute merely five-tenths of one percent of the total livestock inventory of the United States. ${ }^{41}$ 
USDA has two options to identify these few animals. First, as stated above, USDA can work collaboratively with Treasury to remove the animals from the J-list.

Second, USDA, through APHIS, can alter the identification requirements it imposes pursuant to its health rules. Because of health problems with livestock around the world, APHIS has the authority to promulgate regulations requiring all livestock imports to be marked with an indication of the country where it has spent time outside of the US (other than simple transit). In other words, APHIS pursuant to its authority to protect US agriculture already has the ability to require markings which in turn permit an easy identification of whether livestock have come from outside of the United States at any stage of their life and hence would not qualify as born, raised and slaughtered in the United States. This system does not require verification before the slaughter facility, and thus does not face the problem of lack of jurisdiction over livestock producers.

Therefore, in our view, the Presumption of U.S. Origin Rule is the preferred regulatory regime for COOL implementation.

\section{Benefits Analysis}

The benefits side of the COOL equation has been sorely neglected in the national debate. USDA has failed to consider any information relevant to benefits. Industry opponents of COOL have, of course, not volunteered to be helpful in this regard. We examine the overwhelming evidence that substantial benefits arise from country of origin labeling from the consumer perspective, and from the perspective of the industry.

At a fundamental level, our society values information and choice for consumers. Markets cannot operate properly unless information valued by the purchaser is available. Similarly, without meaningful choice, consumers are unable to express their preferences.

The methods of estimating costs and benefits with regard to labeling are very different. For example, in 1994, federal legislation was passed requiring added nutritional labeling on foods covering over two-thirds of the U.S. food system, a far greater swath of the food economy than is covered by the labeling law. That legislation, in contrast with the Labeling Legislation at issue here, required third party verification of nutritional claims by outside laboratories. ${ }^{42}$

The Labeling Legislation is far simpler than nutritional labeling in that only the country of origin is required rather than a chemical analysis of the content of each food item by an independent laboratory. The nature of the benefits depends in large part upon the "utility value" or "satisfaction" attributed to it by the consumer. At a fundamental level, our society values information and choice for consumers. Markets cannot operate properly unless information valued by the purchaser is available. Similarly, without meaningful choice, consumers are unable to express their preferences. Beales, et al (1981) have shown that there are added benefits to be gained by using labels to segment the market allowing for each group of consumers to buy the products corresponding to their willingness to pay. When consumers are unable to distinguish the specific qualities 
of different products, they are not willing to pay as high a price as they would if they were sure that the product was of high quality. ${ }^{43}$

Every survey relevant to the labeling of food has revealed overwhelming consumer support for such labeling and significant concern for information as to where their food is produced. For example:

- Fresh Trends 2002 found that 86 percent of consumer respondents in a national survey favor country of origin labeling. ${ }^{4}$

- The National Public Policy Committee performed a study designed for evaluating producer preferences for agricultural, food and public policy and found that 98 percent of the U.S. agricultural producers favored labeling. ${ }^{45}$

- A multi-university study published in February 2003 on the North Carolina State University website found that a large majority of consumers was concerned about where their food originated. ${ }^{46}$

- The Florida Department of Agriculture and Consumer Services performed a survey in January 2003 finding that $62 \%$ of consumers interviewed would purchase U.S. produce if it had an identifying mark. ${ }^{47}$

There is a substantial body of research on the specifics of food labeling within the discipline of agricultural economics. A recent study regarding consumer willingness-topay for beef labeled as to country of origin was conducted by researchers at Colorado State University and the University of Nebraska-Lincoln and released on March 20, 2003. ${ }^{48}$ Entitled "Country of Origin Labeling of Beef Products: U.S. Consumers' Perceptions," the study used panel survey data to determine consumers' willingness to pay for meat labeled as U.S. origin. The researchers pointed to the specific characteristics that generally motivate consumers as shown in past research:

"Consumers are becoming increasingly concerned with the quality, safety, and production attributes of their food (Caswell, 1998). Consumers' concern with the safety and origin of beef is especially true in light of the recent European and Japanese BSE outbreaks and concerns with E-coli 0157:H7 in U.S. beef. The origin and processes used to produce beef products are not apparent to the consumer through experience, consumption or visual inspection of the product. Therefore, without additional information, consumers are not able to differentiate the origin or processes used to produce the beef products they purchase in the retail store. Production attributes that may be valued by consumers such as organic, non-GMO or country of origin are considered to be credence characteristics (Darby and Karni, 1973, Caswell and Modjuszka, 1996). Truthful labeling of credence characteristics allows the consumer to judge the product before purchasing (Caswell, 1998).",49

The credence characteristics identified by the Colorado State/University of Nebraska study certainly apply to other food items as well as beef, the subject of their analysis. In the beef study, the researchers found that the vast majority of consumers (73\%) in Denver 
and Chicago were willing to pay an $11 \%$ and $24 \%$ premium for steak and hamburger, respectively, that is labeled as to country of origin. An actual auction determined that consumers were willing to pay an average of $19 \%$ more for steak labeled "Guaranteed USA: Born and raised in the U.S." The primary drivers of these results were consumers' food safety concerns, preferences for labeling source and origin information, desires to support U.S. producers, and beliefs that U.S. beef was of higher quality. ${ }^{50}$

This willingness-to-pay calculates into a substantial monetary amount. There are approximately 29,475,000 steers and heifers slaughtered each year. Each animal produces an average of 90 pounds of steak, according to industry experts. Assuming a 10.5\% increase in the $\$ 4.00$ per pound price assumed in the Colorado State study, the aggregate willingness-to-pay is $\$ 812.22$ million for steaks. USDA scanner data for February, 2003, shows that the average steak price is substantially higher at $\$ 4.75$ per pound. ${ }^{51}$ If we adjust for the USDA data, this results in an aggregate willingness-to-pay of $\$ 964.51$ million per year based upon the number of steaks produced by U.S. slaughter steers and heifers and based upon the $72.9 \%$ of consumers that, according to the study, have such a willingness.

As to ground beef, the nation's 275 million consumers ate an average of 29.63 pounds of ground beef per year. ${ }^{52}$ Assuming a $24.3 \%$ increase in the $\$ 1.25$ per pound price assumed in the Colorado State study, the aggregate willingness-to-pay is $\$ 1,777.07$ million.

However, a more accurate ground beef price comes from USDA scanner data for January 2,2003 , which shows a higher price of $\$ 2.16$ per pound. ${ }^{53}$ If we adjust for the USDA scanner data, the result is an aggregate annual willingness-to-pay of $\$ 3,070.78$ million.

The Colorado State study did not calculate the consumer willingness-to-pay for beef roasts, primarily because the survey indicated that consumers were most likely to buy steaks and ground beef as their predominant purchases. ${ }^{54}$ However, if we assume that the lower percentage of money, as between steaks and ground beef, or $10.5 \%$, constitutes the consumer willingness-to-pay for roasts as well as steaks, we can gain a better understanding of the calculation for a larger portion of beef consumed.

The per capita consumption for beef "cuts", which are steaks and roasts, is 38.97 pounds on averaged from 1999 to $2001 .^{55}$ USDA scanner data is $\$ 4.75$ per pound for steaks and $\$ 2.56$ for roasts in February 2003. ${ }^{56}$ An average steer or heifer produces about 90 pounds of retail steaks and 150 pounds of roasts. The adjusted per pound price for "cuts" is thus, $\$ 3.38$ per pound. Assuming that $72.9 \%$ of consumers are willing to pay $10.5 \%$, or 34 cents per pound more for cuts, the aggregate willingness-to-pay is $\$ 2,772.66$ million.

In addition to the actual potential price benefit, there are other benefits that are extremely important but difficult to quantify. For example, the U.S. has spent considerable resources to maintain the confidence in the food supply. As a result, the U.S. food system has been largely insulated from the global food scares such as foot and mouth disease, mad cow disease and other problems. Product labels increase consumer confidence by allowing them to feel informed and knowledgeable, even if they do not actually read the label information. 
The consumer confidence issue incorporates the risk reduction benefit. If the consumer perceives that they are at reduced risk of harm, they feel protected. As an analogy, consumers buy insurance to be protected, but they hope that they will not have to actually utilize the insurance protection they purchased.

Lastly, there is an opportunity to reduce risk and cost due to food safety problems or outbreaks that may originate in a particular country. If processing plants have product segregated and identified, they can avoid some of the tremendous losses emanating from shutdowns and recalls. Further, consumers can avoid products from the affected countries that are already in the retail shelf or in the consumer's pantry. Past recall efforts have been hampered by an inability to procure a large portion of the product because it had already been sold. This is especially the case with regard to perishable foods.

Producers also stand to benefit from food labeling, since an increased willingness to pay on the part of consumers often translates into higher prices and increased returns to producers. Apart from the direct mark-up in prices to reflect the added assurance, another way that prices might increase is as a result of an expansion of demand for the product. When products are displayed side by side with one of lesser quality and the consumer has no way of telling the difference, potential customers might shy away of the market, especially in cases where consumer health might be affected. Rectifying such a situation by providing consumers with the knowledge and information needed and leaving the choice up to them could not only maintain current customers but attract new consumers who are prepared to act on the information given. This would result in an overall increase in the demand for the product and an increase in net returns for producers.

Thus, the benefits of country of origin labeling are significant. The science of quantifying such benefits is well recognized in the field of economics, though few detailed studies have been commissioned on this specific issue. In our view, the clear conclusion is that the benefits of country of origin labeling far outweigh the costs (see cost analysis below).

\section{Record Keeping Cost Analysis}

In any public policy debate over new regulations, it is important to consider not only the costs but also the benefits. The USDA issued an estimate as to the record keeping costs of the Voluntary Guidelines on November 21, 2002. ${ }^{57}$ It was required to do so under the Paperwork Reduction Act of 1995. ${ }^{58}$ Several competing claims have been made by industry as to the cost of the legislation. Those claims have generally not considered benefits.

\section{A. USDA Estimate of Record Keeping Burden}

The USDA published an estimate of record keeping costs (hereinafter "USDA Cost Estimate") in the Federal Register on November 21, 2002. ${ }^{59}$ This notice was published pursuant to the Paperwork Reduction Act that requires federal agencies to estimate the record keeping burdens of new regulations. ${ }^{60}$ The new regulation at issue was the Voluntary Guidelines, not the as-yet-undrafted mandatory rules. The total cost calculated 
was $\$ 1,967.76$ million in the first year for all covered entities. ${ }^{61}$ For the following reasons, we have concluded that the cost estimate was excessively high.

\section{Cost to producers}

The USDA Cost Estimate stated that the producer record-keeping burden would be $\$ 1$ billion. $^{62}$ It assumed that there were 2 million farms, ranches and fishermen (production entities) and that all would implement a system for voluntary labeling. ${ }^{63}$ It further assumed that the time required to develop a record keeping system to comply with the voluntary guidelines is one day. ${ }^{64}$ USDA also estimated that the time required to generate and maintain the records is one hour per month. Lastly, the USDA applied a labor cost of $\$ 25$ per hour. This resulted in a cost estimate of $\$ 400$ million to establish a record keeping system and $\$ 600$ million per year to maintain records, for a total first year cost of \$1 billion.

The first issue is to determine is the number of production entities that will be affected. The October 11, 2002 guidelines profess to affect all down line suppliers including production entities. ${ }^{65}$ For reasons stated above, we question whether the guidelines may cover production entities because they are not within the textual scope of the Labeling Legislation. However, we will assume that such entities may be covered for purposes of critiquing the Cost Estimate.

The second issue is whether the USDA assumption that 2 million producers will be affected is sound. For two reasons, we believe the estimate is far too high. First, all 2 million producers in the country do not produce covered commodities - rather, many produce grains, oilseeds, cotton and rice which are not covered. Oddly, USDA acknowledged this fact in its Voluntary Guidelines but proceeded to ignore it. Statistics from the National Agricultural Statistics Service (NASS) show that there are 1.03 million cattle producers (2003), 75,350 hog farms (2002), 64,170 sheep and goat farms (2002), 12,221 peanut farms (1997), 106,069 fruit and nut farms (1997), and 53,717 vegetable farms (1997). ${ }^{66}$ The total number of producers [excluding fishermen] is thus $1,342,527$ that could potentially be affected. This number is 33 percent less than the USDA estimate.

The third issue is whether the USDA estimate as to number of labor hours to maintain records is correct. The USDA assumed, without articulation, that each producer would require one day to implement a record keeping system and one hour per month to maintain records. The Voluntary Guidelines require records to be maintained for two years. ${ }^{67}$ However, there should be no need for new records, beyond those records kept for other purposes, that are required for producers and growers to show the country of origin of their product.

Livestock producers currently maintain records for taxes, health rules, and other programs that are sufficient to show the origin of their livestock. These records include records on births, animal purchases, feed purchases, sales, inventory and health. Any auditor can glean sufficient information from these records to determine whether 
producer representations are accurate as easily as a tax or accounting auditor can verify the propriety of tax or financial documents. Thus, we envision no new record keeping necessary for livestock producers.

Growers of fresh produce maintain the same records as livestock producers as well as any extra documentation required under the Perishable Agricultural Commodities Act and its regulations. The seed and input records maintained by growers should be sufficient to demonstrate U.S. product. We anticipate that no new records shall be necessary with regard to such growers.

Though the majority of producers of covered commodities produce exclusively U.S. product, we acknowledge that producers of fish, shellfish, cattle, hogs and sheep can procure their product from other countries. Documents showing such purchases are currently maintained for tax and other purposes. Therefore, such producers should have no additional record keeping burden. Indeed, USDA has published a series of documents online to show the types of records that they will require. ${ }^{68}$ All the listed records are common documents maintained by producers.

The fourth issue is whether the USDA applied the proper labor cost to the labor requirements. USDA estimated the value of time for producers at $\$ 25$ per hour. ${ }^{69}$ No basis for that labor cost number was provided. USDA further estimated that each producer would require 8 hours (one time cost) to establish a record keeping system and 12 hours per year to maintain the records. We disagree that added labor will be required to establish a new record keeping system for reasons stated above. However, we will use the USDA labor hour estimate to illustrate the total labor cost miscalculations.

The best data source to estimate the value of each hour of labor comes from the Bureau of Labor Statistics (BLS). BLS data show that the median value of farm labor is $\$ 7.76$ per hour. If we apply the BLS data for labor cost and the aforementioned NASS data on producer numbers to the USDA labor hour estimate for establishing a record keeping system, we find that the labor cost has been reduced by almost $80 \%$ from $\$ 400$ million to $\$ 82.38$ million $[1,342,527$ producers x 8 hours $x \$ 7.67 /$ hour]. Similarly, if we apply the correct labor cost data and the correct producer number data to the USDA labor hour estimate for maintaining the new record keeping system, we find that the first year's labor cost has again been reduced by almost $80 \%$ from $\$ 600$ million to $\$ \mathbf{1 2 3 . 5 7}$ million [1,342,527 producers x 12 hours/yr x $\$ 7.67 / \mathrm{hr}]$.

In sum, we can see no need for any new records beyond those currently maintained by producers to establish origin. Further, if USDA ultimately abandons its attempt to place regulatory burdens upon producers because of lack of jurisdiction over them and adopts the Presumption of U.S. Origin Rule, U.S. producers will not have any documentation requirement or risk of audit. As such, the record keeping burden for producers and growers [excluding fisherman and fish farmers] likely to be imposed by the Labeling Legislation is likely to be very low. 


\section{Cost to Handlers}

The Labeling Legislation allows, but does not require, the Secretary to require "that any person that prepares, stores, handles, or distributes a covered commodity for retail sale maintain a verifiable recordkeeping audit trail." 70 The USDA, through the Voluntary Guidelines, has not only chosen to require such an audit trail, but also has required retailers to ensure that this is done through private contracts. ${ }^{71}$

USDA estimates that there are 100,000 food handlers (including packers, processors, importers, wholesalers, and distributors) in the country. Though it concedes that many do not handle covered commodities, USDA goes on to assume all will choose to comply with the Voluntary Guidelines. Further, USDA presumes that food handlers require 2 days of labor to create a record keeping system at an additional one hour per week to maintain the system. Lastly, USDA establishes a value of $\$ 50$ per hour for labor to generate a $\$ 340$ million record keeping burden. ${ }^{72}$ We disagree with that cost estimate in several fundamental ways.

First, the number of affected entities is too high. There are 2,794 meat product manufacturing plants in the country. ${ }^{73}$ There are 5,680 sellers/shippers of fruits and vegetables. ${ }^{74}$ There are 731 seafood product preparation and packaging companies in the U.S. ${ }^{75}$ Lastly, there are 128 roasted nuts and peanut butter manufacturers. ${ }^{76}$ Thus, the proper number of relevant packers, processors and manufacturers is 9,333 .

As to wholesalers, distributors and importers, there are 2,828 fish and seafood establishments, ${ }^{77} 3,147$ meat and meat products establishments, ${ }^{78}$ and 11,158 handlers of produce79. Census data on establishments gives us a higher number than the number of companies, thus, we reduce the establishment numbers by 5\%. Further, many distributors of one category also distribute other categories, meriting a reduction of another $10 \%$. Thus, the total number of wholesalers, distributors and importers we estimate is 14,563 $[(2,828$ fish $+3,147$ meat $+11,158$ produce handlers $) \times .85]$.

Therefore, the total number of affected entities in the food handler category is 23,896 , or about $76 \%$ less than the USDA estimate.

Further, as with the producer cost estimate, USDA's per hour labor value is too high and without support as to handlers. USDA estimated that handlers will pay a $\$ 50$ per hour wage rate. This wage rate is unrealistically high. The Bureau of Labor Statistics value for the closest category of 18 laborer shows a mean wage rate of approximately $\$ 13.60$ per hour, almost $75 \%$ less than the USDA estimate.

Additionally, because the vast majority of covered commodities are produced within the U.S., most handlers will not have any purchases from foreign origin. There are a few dominant firms in each category. Those dominant firms are most likely to procure product from many sources, including foreign sources. For example, the top four or five meat packers are likely to procure product from other countries. The top four firms control $82 \%$ of the national livestock procurement market in beef, $56 \%$ in swine, and 
$67 \%$ in lamb. ${ }^{80}$ The vast majority of the 2,794 meat product manufacturing plants are likely to procure U.S. product. In other words, the top $1 \%$ of firms in each category are the dominant firms that procure product from overseas. Importers, however, procure all products from foreign sources by definition.

As a result, the record keeping burden for handlers resulting from the Labeling Legislation will be very minimal. All importers must keep records on the country of origin of their product pursuant to customs regulations. Thus, they will not be affected with an increased burden. More than $90 \%$ of other food handlers are unlikely to purchase foreign origin products at the current time. The dominant food handling firms (packers, processors, wholesalers and distributors) are most likely to procure from multiple sources, including U.S. and foreign origin. It is those dominant firms that the record keeping burden will affect the most.

Thus, in our opinion, a maximum of $10 \%$, or 2,390 , of the food handling firms are likely to be affected by an additional record keeping burden as a result of the labeling legislation. Ten percent is probably too high, but we err on the side of conservatism. We will assume at this point that the USDA labor hour estimates are correct for establishing and maintaining records, i.e. that each firm will require 16 hours to establish a system and that 52 hours/year are required to maintain the records.$^{81}$ The aggregate record keeping cost for establishing a system will be about $\$ 520$ thousand [2,390 firms x 16 hours $\mathrm{x}$ $\$ 13.60 /$ hour] . The records maintenance cost for the first year will be $\$ 1.69$ million [2390 x 52 hours/year x $\$ 13.60 /$ hour]. The total first year labor cost for record keeping will be \$2.21 million for those $10 \%$ of food handlers above and beyond the records currently maintained for other purposes.

\section{Cost to Retailers}

All retailers will be required to provide information to consumers as to the country of origin of covered commodities. The Labeling Legislation defines retailers as those licensed by the Perishable Agricultural Commodities Act. ${ }^{82}$ There are 31,000 such licensees. ${ }^{83}$ USDA claims that the each retailer will require 5 days for one person to establish a record keeping system and one hour per day to maintain the records. USDA presumes that the wage rate for such duties is $\$ 50$ per hour. Thus, their total cost estimate is $\$ 625.75$ million for retail record keeping. We think that estimate is again too high.

We do not take issue with the number of retailers. We do think that the estimated time for record keeping is excessive in light of our above discussion relating to the potential to implement a least cost alternative regulatory scheme. The Labeling Legislation requires retailers to inform customers about country of origin through a choice of several means. Retailers do not have specific knowledge of origin claims, but must rely upon supplier representations. Such representations are no different than the host of other representations relied upon in commerce, some of which are independently verifiable and some of which are not. 
Retailers are merely a conduit of labeling claims made by their suppliers. Thus, they need merely to pass such information on to consumers. In the case of covered commodities sold in packages, retailers can merely require that suppliers place the required origin information on the package label. In the case of covered commodities that are sold in bulk form, the origin claims made by suppliers on the boxes and invoices should contain the necessary information for retailers to pass on to their customers. Some of the bulk products could be labeled with placards or signs at the proper display area. Other bulk products, such as apples and oranges, often contain individual stickers which could be modified or added to contain origin information.

Retailers currently maintain detailed records as to purchases and sales. Certainly, there has been a proliferation of product categories in recent years with promotions of higher value products with special attributes including organic, natural, or another branded program. The addition of a category containing origin information would not be a significant feat. Such information should be sufficient for auditors to verify labeling claims. In sum, there will be little need to create a new record keeping system for COOL. Rather, slight changes to existing record keeping and display processes are all that is necessary. Thus, our view is that the USDA time estimate can be reduced by at least $50 \%$.

The USDA labor hour rate is also too high. USDA's Cost Estimate presumed a $\$ 50$ per hour labor cost with no support for that number. The Bureau of Labor Statistics show that the median wage rate for retail wage earners is approximately $\$ 9$ per hour. There may be some involvement of supervisory personnel at a higher median wage rate of $\$ 24.75$ per hour, but such involvement is likely no more than $10 \%$ of the total hours. The weighted average per hour wage rate is thus $\$ 10.75$ per hour [ $(90 \% \times$ x $\$ 9.00 /$ hour $)+(10 \% \times$ $\$ 24.75 /$ hour)], or almost $80 \%$ less than the USDA Cost Estimate.

The total cost for establishing a record keeping system for retailers in the first year is, thus, $\$ 6.67$ million [31,000 retailers x $\$ 10.75$ /hour x 20 hours]. The total first year cost for maintaining the marginal increase in records is $\$ 61$ million [31,000 retailers $\mathrm{x}$ $\$ 10.75 /$ hour $x 183$ hours]. The total first year record keeping cost is, therefore, $\mathbf{\$ 6 7 . 6}$ million for retailers, almost $90 \%$ less than the USDA estimate.

\section{Total Record Keeping Cost}

Assuming that USDA adopts a least cost alternative program for complying with the Labeling Legislation, we believe that the total record keeping cost for producers, handlers and retailers should be between $\mathbf{\$ 6 9 . 8 6}$ million [ $\$ 0$ producer cost $+\$ 2,210,272$ handler cost $+\$ 67,649,750$ retailer cost] and $\$ \mathbf{1 9 3 . 4 3}$ million $[\$ 123,566,185$ producer cost + $\$ 2,210,272$ handler cost $+\$ 67,649,750$ retailer cost]. These more realistic estimates constitute a $90-95 \%$ reduction in the USDA estimate. The reduction arises from errors in calculation by USDA and from a labeling program that pursues the goal of regulatory efficiency by eliminating onerous requirements and piggy-backing on existing records kept in the stream of commerce. 
Considering that U.S. consumers purchase and eat approximately 236.4 billion pounds of covered commodities, ${ }^{84}$ the per pound cost of record keeping for labeling is between three-hundredths (3/100ths) and eight-hundredths (8/100ths) of a cent per pound. There is no reason to believe that this small cost impact should lead to consumers avoiding covered commodities (such as beef) and substituting non-covered commodities (such as poultry).

\section{B. Other Studies Relating to Cost}

We are aware of other claims and position papers which claim to establish very high costs arising from the Labeling Legislation. For example, a livestock economist from Texas A\&M University, Dr. Ernie Davis, has stated publicly that COOL will cost the beef industry $\$ 8.9$ billion. We are unaware that any data or analysis supporting that estimate has been released. We disagree that the cost of compliance will be that high.

We are aware that a position paper has been released and submitted to USDA by Cattle Buyers Weekly (a beef industry trade publication) and Sparks Companies, Inc. (a consulting firm for agri-businesses) ${ }^{85}$ The Sparks position paper claims that the total cost of labeling will between $\$ 3.6$ and 5.6 billion. We disagree for several reasons.

First, Sparks alleges that a substantial new and complex record keeping system will be required by all levels of the supply chain. However, the existing record keeping systems will be largely sufficient to comply with USDA's list of records that will satisfy an audit. ${ }^{86}$ Indeed, large amounts of information are currently collected and maintained in the food industry. Labeling as to origin is already required for imports. The addition of a single piece of additional information is not likely to be a complex task.

Second, Sparks asserts that mandatory animal identification will prove necessary. The Labeling Legislation specifically prohibits mandatory animal identification. Further, there is no reason that such a program is necessary for COOL. We question why it should be necessary to identify animals individually and not, for example, individual string beans.

Third, Sparks claims that the complexities of implementing COOL in the beef industry will create a competitive disadvantage for beef in relation to other meat protein sources. However, as stated above, the implementation of labeling is not complex. Packers and processors of livestock and fish will have to group product of foreign origin separate from U.S. origin product. This task will not require individual animal identification. It will require a change in data entry and labels. It will also require separate runs for batch ground hamburger and sausage. These challenges are no different from those posed by the newly proliferating specialty product categories, such as the Certified Angus Beef program, which are currently in existence.

The Sparks/CBW position paper admits it assumes a "worst case scenario" in its conclusions. However, USDA has been clear it does not intend to impose such a worst case scenario upon industry. Therefore, the conclusions in that document are not sound in our view. 


\section{CONCLUSION}

Country of origin labeling is an important part of providing consumers with the information and choice that they desire. The reduction of food system risk and the preservation of consumer confidence in the food system are very important benefits. Every credible study has shown that consumers value this information and some studies show a significant willingness-to-pay to get this information. The combination of survey data and experimental auction data that is currently available lead us to the conclusion that the consumer willingness-to-pay for labeling amounts to billions of dollars across all covered commodities.

Conversely, the costs and complexity of labeling have been overblown, often to absurd levels. We disagree with the estimates of cost provided thus far by USDA and others. Our cost estimate of $\$ 69.86$ million to $\$ 193.43$ million is very minimal in comparison to the vast size of the food and agriculture economy. The benefits substantially outweigh the costs of labeling.

Lastly, the regulatory choice for implementation of the Labeling Legislation should be the Presumption of U.S. Origin Rule. This rule is the least intrusive option for private industry, and stands the best chance for passing legal muster. In our view, it is overwhelmingly the best choice in light of the significant drawbacks of the alternative regulatory schemes.

- Director of the International Agricultural Trade \& Policy Center and Professor of Food and Resource Economics, University of Florida.

.. Associate Professor of Agricultural Economics and Extension Specialist, Agricultural Law and Policy, Kansas State University. Member of Kansas and Nebraska Bars.

... ALFA Eminent Scholar and Professor of Agricultural Economics, Auburn University.

.... Charles F. Curtiss Distinguished Professor in Agriculture and Professor of Economics, Iowa State

University. Member of the Iowa Bar.

..... Professor of Agricultural Economics, Purdue University.

1 Farm Security and Rural Investment Act of 2002, Subtitle D-Country of Origin Labeling, Sec. 282(a)(1).

2 Labeling Legislation, $\S \S 281(\mathrm{a})(1)$.

3 Id. at $\$ 282(\mathrm{a})(2)$.

4 Id. at $\S 282(\mathrm{a})(1)$.

5 Id. at $\S 282(\mathrm{c})$.

6 Id. at $\S 282(\mathrm{e})$.

7 Id. at $\S 282(\mathrm{~d})$.

8 Id. at $\S 282(\mathrm{f})(1)$.

9 We note that recent news reports quote Tom Ridge, Secretary of the Department of Homeland Security, as appearing to endorse a national animal identification plan due to fears of bioterrorism.

10 Labeling Legislation, supra at $\S 282(a)$.

${ }_{11}$ Section 281(6) defines retailers according to the definition set forth in the Perishable Agricultural Commodities

Act of 1930 (7 U.S.C. 499a(b)). That provision exempts retailers selling less than $\$ 230,000$ fruits and vegetables

annually. A strong argument could be made that Congress meant to include all covered commodities in that gross sales threshold here. We do not argue this point further.

12 Labeling Legislation at $\S 282(\mathrm{~b})$. 
13 Id. at $\S 292(d)$.

14 See, id. at $\S 281(1),(2),(5)$, and (7).

15 Id. at $\S 285$.

16 Id. at $\S 284(\mathrm{a})$.

${ }_{17}$ Federal Register, "Establishment of Guidelines for the Interim Voluntary Country of Origin Labeling of

Beef, Lamb, Pork, Fish, Perishable Agricultural Commodities, and Peanuts Under the Authority of the

Agricultural Marketing Act of 1946," Vol. 67, No. 198, pp. 63367-63375, October 11, 2002 (hereinafter

Voluntary Guidelines).

18 Labeling Legislation, $\S 284(\mathrm{~b})$.

19 Id. at $\S 283(\mathrm{c})$.

20 Id. at $\$ 283($ b).

${ }_{21}$ See, id. at $\S 283$ (a) which refers to the enforcement provisions of section 253 (7 U.S.C. $\S 1636 b$ ).

227 U.S.C. $\$ 1636 b(a)(3)$.

23 Voluntary Guidelines, supra at pg. 63375.

24 "Country of Origin Labeling: Examples of records that may be useful for COOL verification purposes,"

USDAAMS website, www.ams.usda.gov/cool/records.htm.

25 Voluntary Guidelines, supra at pg. 63369.

${ }_{26}$ Working Party Report, Certificates of Origin, Marks of Origin, Consular Formalities, adopted 17

November 1956, BISD 5S/102, para. 13.

2719 U.S.C. $1304(\mathrm{a})$ :

Except as hereinafter provided, every article of foreign origin (or its container, as provided in subsection (b) hereof) imported into the United States shall be marked in a conspicuous place as legibly, indelibly, and permanently as the nature of the article (or container) will permit in such manner as to indicate to an ultimate purchaser in the United States the English name of the country of origin of the article. The Secretary of the Treasury may by regulations-

(3) Authorize the exception of any article from the requirements of marking if-

(J) Such article is of a class or kind with respect to which the Secretary of the Treasury has given notice by publication in the weekly Treasury Decisions within two years after July 1, 1937, that articles of such class or kind were imported in substantial quantities during the five-year period immediately preceding January 1, 1937, and were not required during such period to be marked to indicate their origin: Provided, That this subdivision shall not apply after September 1, 1938, to sawed lumber and timbers, telephone, trolley, electric-light, and telegraph poles of wood, and bundles of shingles; but the President is authorized to suspend the effectiveness of this proviso if he finds such action required to carry out any trade agreement entered into under the authority of sections 1351, 1352, 1353, 1354 of this title, as extended;

28 See 19 U.S.C. $\S 1304(\mathrm{a})(3)(\mathrm{H})$.

${ }_{29}$ See generally, 9 CFR 93.418, 9 CFR 92.420, 9 CFR 93.505 and 9 CFR 93.517 stating that ruminants and swine imported for immediate slaughter from Canada need not be accompanied by a health certificate. 3019 CFR 134.33.

${ }_{31}$ See, 9 CFR 93.407, 9 CFR 93.417(b) and 9 CFR 93425 requiring that all imported animals, including those from Canada and Mexico, be accompanied by documentation as to, inter alia, country of origin. 32 USDA statutory authority was derived from 21 USC $\S \S 102-121$. Those provisions were repealed and replaced by the Animal Health Protection Act passed as part of the Farm Security and Rural Investment Act of 2002, Title X, Subtitle E, sec. 10401-10418. This new provision consolidates various older laws into one statute and appears to provide USDA the authority to regulate the importation of animals into the United States. 7 USC $\S \S 8301-8316$.

3319 CFR Sec. 134.31 (Requirements of other agencies) provides that:

"Nothing in this subpart shall be construed as excepting any article (or its container) from the particular requirements of marking provided for in any other provision of any law, such as those of the Federal Trade Commission, Food and Drug Administration, and other agencies." ${ }_{34}$ See, search engine at USDA-FAS website, http://www.fas.usda.gov/ustrade/USTImHS10.asp?QI=. 359 CFR 93.427(c)(1). 
${ }_{36}$ See, FAS website search engine, supra.

$37 \mathrm{Id}$.

${ }_{38}$ See, 9 CFR 517.

39 National Agricultural Statistics Service-USDA, Cattle, obtained from the Internet at

http://usda.mannlib.cornell.edu/reports/nassr/livestock/pct-bb/cat10103.txt on May 5, 2003.

40 National Agricultural Statistics Service-USDA, Sheep, obtained from the Internet at http://usda.mannlib.cornell.edu/reports/nassr/livestock/pgg-bbs/shep0702.txt on May 5, 2003.

${ }_{41}$ As of July 1, 2003, the latest data available, all sheep and lambs in the United States totaled 8.1 million head. National Agricultural Statistics Service-USDA, Sheep, obtained from the Internet at http://usda.mannlib.cornell.edu/reports/nassr/livestock/pgg-bbs/shep0702.txt on May 5, 2003. On January 1, 2003, all cattle and calves in the United States totaled 96.1 million head. National Agricultural Statistics Service-USDA, Cattle, obtained from the Internet at http://usda.mannlib.cornell.edu/reports/nassr/livestock/pct-bb/cat10103.txt on May 5, 2003. As of March 1, 2003, all hogs and pigs in the United States totaled 58.1 million head. National Agricultural Statistics Service-USDA, Quarterly Hogs and Pigs, obtained from the Internet at http://jan.mannlib.cornell.edu/reports/nassr/livestock/php-bb/2003/hgpg0303.txt on May 5, 2003. $42 \mathrm{~A}$ major study of the costs and benefits of nutritional labeling was performed by two teams of economists. One team studied the estimated costs of nutritional labeling while the other team worked independently to estimate the benefits of the program. The two teams were required because the methods of studying benefits are generally different than the methods for estimating costs. Further, it was determined beneficial if the teams were unable to coordinate results in any way. The resulting study has been praised as a model for future studies of the same type. For the cost analysis, see, "Compliance Cost Estimates of Food Labeling Regulations: Final Report No. 233U-3972-02DFR,” Research Triangle Institute, RTI Park, NC, 158 pp. (1991).

${ }_{43}$ Beales, H., R. Craswell, and S. Salop, “The Efficient Regulation of Consumer Information,” Journal of Law and Economics, 24 (1981); 491-544.

44 The Packer Magazine. Fresh Trends 2002. Shawnee Mission, KS. 2002.

${ }_{45}$ Lubben, Simons, Bills, Meyer and Novak. "The 2002 Farm Bill: U.S. Producer Preferences for Agricultural, Food, and Public Policy.” National Public Policy Committee Publication 2001-02. Sept., 2001 at 26 .

46 "Food from our Changing World: The Globalization of Food and How Americans Feel About It," online at http://sasw.chass.ncsu.edu/global-food/foodglobal.html.

${ }_{47}$ See, http://www.doacs.state.fl.us/press/01302003.html.

${ }_{48}$ Umberger, Feuz, Calkins, and Sitz, "Country of Origin Labeling of Beef Products: U.S. Consumers'

Perceptions," Presented at the 2003 FAMPS Conference: "Emerging Roles For Food Labels: Inform, Protect, Persuade," Washington, DC, March 20-21, 2003, available online at

http://dare.agsci.colostate.edu/extension/cool.pdf.

49 Id. at 2.

50 Id. at 1.

51 See, www.ers.usda.gov/Data/meatscanner/.

52 See data presented by National Cattlemen's Beef Association derived from USDA and Cattle Fax at www.beef.org/dsp/dsp_locationContent.cfm?locationId=219, click on March 2003, table 3.3.

53 See, www.ers.usda.gov/Data/meatscanner/.

54 Umberger, supra at 15 and Table 1.

${ }_{55}$ NCBA data, supra at www.beef.org/dsp/dsp_locationContent.cfm?locationId=219, click on March 2003, table 3.3 .

${ }_{56} \mathrm{See}$, www.ers.usda.gov/Data/meatscanner/.

${ }_{57}$ See, Cost Estimate, supra.

5844 U.S.C. chap. 35.

59 Cost Estimate.

${ }_{60}$ See generally, 44 U.S.C. 3501.

${ }_{61}$ Cost Estimate, supra at pg. 70206.

62 Id. at 70205.

63 Id.

64 Id. 
65 Voluntary Guidelines, supra at pg. 63374.

${ }_{66} \mathrm{We}$ have no data on the number of fisheman and fish farms. However, because a large percentage of fish and seafood consumption is of foreign origin, most entities have systems in place to satisfy COOL

requirements.

67 Voluntary Guidelines, supra at 63374.

68 "Country of Origin Labeling: Examples of records that may be useful for COOL verification purposes," USDAAMS website, www.ams.usda.gov/cool/records.htm.

${ }_{69}$ Cost Estimate, supra at 70206.

70 Farm Bill Labeling Subtitle, §282(d).

71 Voluntary Guidelines, supra at 63374.

72 Cost Estimate, supra at 70206.

731997 Economic Census, Manufacturing, U.S. Bureau of the Census (2002).

74 Red Book Credit Services (The Red Book), Volume 128, March 2002, Vance Publishing Corporation, Shawnee Mission, KS.

751997 Economic Census, Manufacturing, supra.

76 Id.

771997 Economic Census, Wholesale Trade, U.S. Bureau of the Census (2001).

78 Id.

79 The Red Book, supra.

802002 Annual Report of the Grain Inspection, Packers and Stockyards Administration, supra at 35.

81 Large firms will likely require more time, but small firms will require less.

82 Labeling Legislation, supra, $\S 281(6)$.

83 USDA Cost Estimate, supra, pg. 70206.

${ }_{84}$ USDA Economic Research Service Food Consumption statistics indicate per capita consumption in 2000 at 113.6 pounds for red meats, 15.2 pounds for fish and shellfish, 5.7 pounds for peanuts, 279.4 pounds for fruit and 428.3 pounds for vegetables (USDA/Economic Research Service at http://www.ers.usda.gov/Data/FoodConsumption. Given the U.S. population of 280.8 million in 2000, yields a total consumption of 236.4 billion pounds for all products.

85 "COOL Cost Assessment: Prepared by the Sparks/CBW Consortium," Sparks Companies, Inc., April 2003.

${ }_{86}$ See, "Country of Origin Labeling: Examples of records that may be useful for COOL verification purposes," USDA-AMS website, www.ams.usda.gov/cool/records.htm. 